\title{
A COST VARIATION ANALYSIS STUDY OF DRUGS USED IN THE MANAGEMENT OF BENIGN PROSTATIC HYPERPLASIA AVAILABLE IN THE INDIAN MARKET
}

\author{
VIBHA RANI ${ }^{1 *}$, SAILAXMI VENEPALLY ${ }^{2}$ \\ ${ }^{1}$ Department of Pharmacology, Malla Reddy Medical College for Women, Suraram, Hyderabad, India. ${ }^{2}$ Department of Pharmacology, \\ Pratima Institute of Medical Sciences, Karimnagar, Telangana, India. Email: vibhabhat1984@gmail.com
}

Received: 4 March 2021, Revised and Accepted: 14 April 2021

\section{ABSTRACT}

Objectives: The objectives of the study are to evaluate the cost variation and cost ratio of different brands of the drugs used in the treatment of benign prostatic hyperplasia (BPH).

Methods: The cost of alpha-blockers and 5 alpha-reductase inhibitors used in the treatment of BPH was noted from CIMS (Oct 2019-Jan 2020), Drugs Update, and Medline. The differences between the maximum and minimum cost of various brands of the same drug were analyzed and percentage variation in the cost was calculated. The results of the study were expressed in absolute numbers and percentages.

Results: All the drugs used in the treatment of BPH are only available in tablet and capsule forms, in 10 different dosages and in 242 different brand names, of which $10 \mathrm{mg}$ alfuzosin and $2.5 \mathrm{mg}$ finasteride have the highest (518) and lowest (14) percentage of cost variation, while $0.4 \mathrm{mg}$ tablet form of tamsulosin is available in the maximum number of brands- 41 .

Conclusion: This pharmacoeconomic study reveals that there is wide variation in the cost of most of the drugs used in the treatment of BPH. Therefore, it is very much essential for both government and pharmaceutical companies to make combined efforts to reduce the cost of these drugs, which will reduce the economic burden on the patients and also reduce the overall health care costs.

Keywords: Benign prostatic hyperplasia, Cost variation, Cost ratio, Drugs, Pharmacoeconomics.

(C) 2021 The Authors. Published by Innovare Academic Sciences Pvt Ltd. This is an open access article under the CC BY license (http://creativecommons.org/ licenses/by/4.0/) DOI: http://dx.doi.org/10.22159/ajpcr.2021v14i6.41291. Journal homepage: https://innovareacademics.in/journals/index.php/ajpcr

\section{INTRODUCTION}

Benign prostatic hyperplasia (BPH) is a noncancerous condition in which there is multiplication of prostatic stromal and epithelial cells which leads to enlargement of prostatic gland [1]. It is the most common medical condition affecting elderly males and its prevalence increases from $25 \%$ in the age group of $40-49$ years to $80 \%$ in $70-79$ years age [2]. The risk factors of BPH are divided into non-modifiable factors such as age, genetic, and modifiable factors such as testosterone, obesity, diabetes, diet, physical activity, and inflammation [3]. Symptoms of BPH include frequent urination, inability to urinate, weak stream, trouble starting to urinate, and if untreated may lead to complications such as frequent urinary tract infections, bladder damage, and kidney damage $[4,5]$.

The medical management of BPH includes alpha-blockers such as prazosin, alfuzosin, doxazosin, silodosin, tamsulosin, and terazosin. These drugs act by blocking the alpha receptors present in the prostate gland thus relaxes the muscles of the prostate and urethra but they do not reduce the size of the prostate and are associated with side effects such as headache and dizziness. The second group of drugs is the 5 alpha-reductase inhibitors, which includes finasteride and dutasteride. These drugs act by blocking the production of dihydrotestosterone, a male sex hormone, thereby shrinking the prostate gland and their side effects include fatigue and retrograde ejaculation [6].

India is a hub of branded generic market, which means that the doctors, instead of prescribing underlying formulation of drugs, prescribe the brand name of the drugs. Doctors many times prescribe leading brands though there is the availability of affordable brands and patients are ignorant about cheaper substitutes of drugs, they sometimes buy the expensive drug brands recommended by their doctors. This will have a direct effect on patient's finance adversely if the costly brand is prescribed, especially in conditions like $\mathrm{BPH}$, in which patients need treatment for prolonged duration. These reasons have enabled the government to take a step forward to make essential drugs accessible to patients at reasonable prices [7]. In India, National Pharmaceutical Pricing Authority (NPPA) controls and regulates the prices of pharmaceutical drugs in India and it has limited authority to fix, review, and justify pharmaceutical prices under the Drug Prices Control Order (DPCO), 1995 [8].

In developing countries like India, pharmacoeconomic analysis of drugs plays a key role for policy-makers in analyzing the affordability and also access to the rational use of drugs. Cost variation analysis of drugs is a type of pharmacoeconomic evaluation method, which compares the costs of two or more drugs without regard to outcome. By this evaluation method, one can understand different brands of the same drug, inter-brand cost variation, the best cost-effective drug available which will guide doctors in selecting the right drug for a particular disease condition [9].

The present study was aimed at investigating the cost differences in various brands of drugs used in the treatment of $\mathrm{BPH}$, following which a cheaper effective brand can be prescribed, which will ensure better patient adherence to drugs, good compliance and will also reduce total healthcare expenditure. Medical management is the main modality of treatment in BPH and also as it is more common in the aging population who also suffer from other co-morbidities such as hypertension and diabetes, thus requiring multiple daily medications. There are no studies in Indian scenario, which compare the cost of different drugs used in the management of BPH. The study has the following objectives: (1) To evaluate cost variation of different brands of the drugs used in the treatment of BPH and (2) to assess cost ratio of the drugs used in the treatment of $\mathrm{BPH}$. 


\section{METHODS}

The cost of alpha-blockers - prazosin, terazosin, doxazosin, alfuzosin, tamsulosin, silodosin, and 5 alpha-reductase inhibitors - finasteride and dutasteride which are used in the treatment of BPH and available in the Indian market was noted from CIMS (Oct 2019-Jan 2020), Drugs Update, and Medline. The cost of the drugs in the same strength and form which are manufactured by different pharmaceutical companies was noted. For oral forms of the drug, price was calculated per 10 tablets. All the prices were calculated in Indian rupees. Drugs with fixed-dose combinations, two or more drugs manufactured by the same company in the same strength or form were excluded from the study.

The cost ratio was calculated using the formula:

$$
\text { Cost ratio }=\frac{\text { Cost of most expensive brand }}{\text { Cost of the least expensive brand }}
$$

This will tell how many times the costliest brand costs more than the cheapest one in each group.

The difference in the maximum and minimum price of the same drug formulation was calculated.

The percentage variation in cost was calculated using the formula: Cost of most expensive brand Cost variation $(\%)=\frac{- \text { Cost of the least expensive brand }}{\text { Cost of the least expensive brand }} \times 100$

Based on percentage variation, the cost of all the drugs was divided into four groups as follows:

Group 1: $<24.99 \%$

Group 2: 25-49.99\%

Group 3: $50-99.99 \%$

Group 4: 100-499.99\%.

\section{RESULTS}

All the drugs used in the management of BPH are only available in two oral forms-tablet and capsule. These drugs are available in 10 different dosages and 242 different brand names. Table 1 shows cost variation of various drugs used in benign prostatic hypertrophy.

Prazosin is available only in tablet form, in 4 different dosages, with 29 different brands. Furthermore, terazosin is available in 3 different dosage forms, with 26 different brands. There are 3 dosage forms with 11 brands of doxazosin, while alfuzosin is available in 2 dosages with 32 brands. Tamsulosin is available in both tablet and capsule form, of which tablet is available in 51 different brands and capsule in 25 brands. Silodosin is available in both tablet and capsule forms with 12 brands each. Finasteride is available in 3 different dosages in tablet form with 32 different brands, while dutasteride is available in 2 dosages, in both tablet and capsule form with 4 brands each. Alfuzosin is available in $10 \mathrm{mg}$ and $2.5 \mathrm{mg}$ tablet form. Finasteride is only available in tablet form in 3 different dosages and dutasteride is available in both tablet and capsule form with 4 brands each. Of all the drugs in this group, $10 \mathrm{mg}$ alfuzosin and $2.5 \mathrm{mg}$ finasteride have the highest and lowest percentage of cost variation, while $0.4 \mathrm{mg}$ tablet form of tamsulosin is available in the maximum number of brands. Table 2 shows the classification of drugs based on the percentage of cost variation of drugs and it was highest in group 3 with 15 formulations. Mean cost of alpha-blockers and 5 alpha-reductase inhibitors used in BPH is shown in Graphs 1 and 2, respectively.

\section{DISCUSSION}

The main objective of the study was to identify the cost variation and cost ratio of different brands of drugs used in the medical management of BPH in the Indian market and this study reveals that there is huge cost variation among various formulations of these drugs. Furthermore, similar studies done in the past with anti-hypertensive drugs [10], anxiolytic drugs [11], drugs used in thromboembolic disorders [12], and anticancer drugs [13] have also given conclusion on huge cost variation of drugs. The results of the study indicate that despite the measures of cost control of drugs in India, under Drug Price Control Order (DPCO) initiative by the Government of India, significant interbrand cost variations still exist in the Indian pharmaceutical market. The main objective of DPCO was to bring down or even remove such inter-brand cost variations, but the results of the study clearly indicate that to date it has not yet achieved its objectives completely [14].

Table 1: Cost variation of various drugs used in benign prostatic hypertrophy

\begin{tabular}{|c|c|c|c|c|c|c|c|}
\hline Drugs & Forms & Dose (mg) & No. of brands & Minimum price (INR)* & Maximum price (INR)* & Cost ratio & Cost variation (\%) \\
\hline \multirow[t]{4}{*}{ Prazosin } & Tablet & 1 & 3 & 21 & $60-114$ & $2.8-2.2$ & 185 \\
\hline & Tablet & 2 & 1 & 97 & 125 & 1.6 & 100 \\
\hline & Tablet & 2.5 & 11 & 50 & & & 128 \\
\hline & Tablet & 5 & 14 & 75 & & & 66.6 \\
\hline \multirow[t]{3}{*}{ Terazosin } & Tablet & 1 & 14 & 40 & 182 & 4.5 & 355 \\
\hline & Tablet & 2 & 9 & 107 & 270 & 2.5 & 152 \\
\hline & Tablet & 5 & 3 & 161 & 540 & 3.3 & 235 \\
\hline \multirow[t]{3}{*}{ Doxazosin } & Tablet & 1 & 5 & 18 & 39 & 2.1 & 116 \\
\hline & Tablet & 2 & 4 & 25 & 74 & 2.9 & 196 \\
\hline & Tablet & 4 & 2 & 87 & 100 & 1.1 & 15 \\
\hline \multirow[t]{2}{*}{ Alfuzosin } & Tablet & 5 & 2 & 59 & 89 & 1.5 & 51 \\
\hline & Tablet & 10 & 30 & 73 & 451 & 6.1 & 518 \\
\hline \multirow[t]{4}{*}{ Tamsulosin } & Tablet & 0.2 & 10 & 40 & 107 & 2.6 & 168 \\
\hline & Capsule & 0.4 & 41 & 39 & 225 & 5.7 & 477 \\
\hline & & 0.2 & 10 & 34 & 94 & 2.7 & 176 \\
\hline & & 0.4 & 15 & 40 & 225 & 5.6 & 463 \\
\hline \multirow{4}{*}{ Silodosin } & Tablet & 4 & 2 & 180 & 250 & 1.3 & 33 \\
\hline & Capsule & 8 & 2 & 259 & 319 & 1.2 & 23 \\
\hline & & 4 & 6 & 128 & 174 & 1.3 & 36 \\
\hline & & 8 & 18 & 185 & 380 & 2 & 105 \\
\hline \multirow[t]{3}{*}{ Finasteride } & Tablet & 1 & 16 & 29 & 110 & 3.7 & 279 \\
\hline & Tablet & 2.5 & 3 & 63 & 71 & 1.1 & 14 \\
\hline & Tablet & 5 & 13 & 60 & 190 & 3.1 & 217 \\
\hline \multirow[t]{2}{*}{ Dutasteride } & Tablet & 0.5 & 4 & 107 & 174 & 1.6 & 62 \\
\hline & Capsule & 0.5 & 4 & 166 & 260 & 1.5 & 57 \\
\hline
\end{tabular}


Table 2: Classification of drugs based on percentage of cost variation

\begin{tabular}{lll}
\hline Groups & Cost variation of drugs (\%) & No. of formulations \\
\hline Group 1 & $<49.99$ & 5 \\
Group 2 & $50-99.99$ & 4 \\
Group 3 & $100-499.99$ & 15 \\
Group 4 & $>500$ & 1 \\
\hline
\end{tabular}



Graph 1: Mean cost of alpha-blockers used in BPH



Graph 2: Mean cost of 5 alpha-reductase inhibitors used in BPH

Pharma sector in India is a big branded generic market with the availability of over 1 lakhs of different formulations, which means that the doctors, instead of prescribing underlying formulations, prescribe the brand of each medicine to patients. Despite the availability of affordable brands, doctors having tie-ups with different pharmaceutical companies, in many cases prescribe leading brands which are priced at a premium rate. However, the truth is that a costly brand of the same generic drug is never superior to its cheaper counterpart. Besides, due to no proper government policies, lack of uniform auditing system, huge competition between pharmaceutical companies has resulted in huge cost variation among the drugs [15]. All these factors lead to huge economic burden on patients, especially who belong to low socioeconomic class leading to an increase in Out of Pocket (OOP) expenditure from the patients. Unnecessary operations, poor government health facilities, lack and ignorance about insurance schemes, huge doctor fees, and high cost of drugs are the reasons for OOP expenses of which high cost of drugs is found to be the main reason [16].

Therefore, there is an urgent need of controlling cost of various drugs available in the Indian market. In 2018, the Government of India had introduced a National Health Protection Scheme-Ayushman Bharat with a goal of reaching approximately 50 crore beneficiaries along with providing coverage up to 5 lakh rupees per family per year for secondary and tertiary care hospitalization [17]. Pradhan Mantri Bhartiya Janaushadhi Kendra a good initiate by the Government of India in 2018, with the aim of supplying generic drugs to the patients, quality control of drugs and also for regularization of drug prices in India [18]. The new Competency-based Medical Education-pharmacology curriculum introduced by the Medical Council of India in 2018 has also introduced prescription auditing ( $\mathrm{PH} 3.2$ ) as one of the competencies to be taught to medical students [19].

Out of 851 drugs under the latest price control by DPCO in2019, it was found that none of the drugs involved in the treatment of BPH were included in the study. To make drugs affordable to all, the government must bring the majority of drugs under the DPCO list. Although it has been mandatory by the government for all doctors to write prescriptions which includes generic names of drugs, this rule is rarely followed by many. There needs to be a strong audit of the prescriptions of the doctors so that stringent action can be taken on doctors who are not following the rules [20]. However, just enforcing rules on doctors to prescribe only drugs in generic names without addressing the issues raised by them is definitely not a wise approach. Hence, there needs to be a step-wise strategy to promote the use of generic drugs [21].

Hence, it is mandatory for not only for the government but also for all health care providers and public to make combined efforts to implement strict policies, due to which the costs of both generic and branded drugs can be reduced, thus making it affordable to the common man.

\section{CONCLUSION}

This study shows that there is a wide variation in the cost of most of the drugs used in BPH which are available in India. Health care providers must be aware of the availability of low-cost brands or generics and they also need to have a moral responsibility to consider drug prices before prescribing. Furthermore, given the magnitude of inter-brand price variations observed among the drugs in this study, it is strongly recommended that the government authorities need to revise their pricing policies on drugs, ensure regulatory checks on pharmaceutical companies to bring all brand prices within ceiling prices, thus reducing economic burden on patients and health care system. Prescribing doctors have to write rational prescriptions and need to adhere to the World Health Organization (WHO) standards for prescriptions. This will definitely make quality health care accessible to India's present and future generations.

\section{AUTHORS' CONTRIBUTIONS}

Dr. Vibha Rani: Concept and design of the study, extensive literature search, data analysis, statistical analysis, manuscript preparation, manuscript editing, and reviewing the manuscript. Dr. Sailaxmi Venepally: Extensive literature search, data analysis, statistical analysis, manuscript preparation, manuscript editing, and reviewing the manuscript.

\section{CONFLICTS OF INTEREST}

Nil.

\section{AUTHORS' FUNDING}

Self.

\section{REFERENCES}

1. Kapoor A. Benign prostatic hyperplasia (BPH) management in the primary care setting. Can J Urol 2012;19:10-7.

2. Praveen R. Benign prostatic hyperplasia: An updated review. Int Res J Pharm 2013;4:45-51

3. Patel ND, Parsons JK. Epidemiology and etiology of benign prostatic hyperplasia and bladder outlet obstruction. Indian J Urol 2014;30:170-6. 
4. Madersbacher S, Sampson N, Culig N. Pathophysiology of benign prostatic hyperplasia and benign prostatic enlargement: A mini-review. Gerontology 2019;65:458-64.

5. Anwar AR, Basha AA. Benign prostatic hyperplasia and its association with ABO blood group system. J Med Sci Clin Res 2015;3:6095-9.

6. De la Rosette JJ, Alivizatos G, Madersbacher S, Perachino M, Thomas D, Desgrandchamps $\mathrm{F}$, et al. EAU guidelines on benign prostatic hyperplasia (BPH). Eur Urol 2001;40:256-63.

7. Andrade C, Rao TS. Prescription writing: Generic or brand? Indian J Psychiatry 2017;59:133-7.

8. Narula S. Current drug pricing status in India. Pharmacoeconomics 2015;1:e101

9. Atal S, Atal S, Deshmankar B, Nawaz SA. Cost analysis of commonly used drugs under price control in India: Assessing the effect of drug price control order on brand price variation. Int J Pharm Pharm Sci 2016;8:315-21

10. Kamath L, Satish GR. Cost variation analysis of antihypertensive drugs available in Indian market: An economic perspective. Int J Pharm Sci Res 2016;7:2050-6.

11. Chawan VS, Badwane SV, Gawand KV, Chhaya MU. Analysis of price variation amongst different formulations of anxiolytic drugs available in Indian market. Int J Res Med Sci 2016;4:2398-401.

12. Ray A, Najmi A, Khandelwal G, Sadasivam B. A cost variation analysis of drugs available in the Indian market for the management of thromboembolic disorders. Cureus 2020;12:e7964.
13. Kolasani BP, Malathi DC, Ponnaluri RR. Variation of cost among anti-cancer drugs available in Indian market. J Clin Diagn Res 2016;10:FC17-20

14. Bhaskarabhatla A, Chatterjee C, Anurag P, Pennings E. Mitigating regulatory impact: The case of partial price controls on metformin in India. Health Policy Plan 2017;32:194-4.

15. Mir SA. Cost variation analysis of different brands of commonly prescribed antihypertensive drugs, available in Indian market: A pharmacoeconomic study. Int J Basic Clin Pharmacol 2018;7:556-60.

16. Cyril JK. Pharmacy pricing and out-of-pocket health care expenditure in India. Biomed J Sci Tech Res 2018;6:1-2.

17. Angell BJ, Prinja S, Gupt A, Jha V, Jan S. The Ayushman Bharat Pradhan Mantri Jan Arogya Yojana and the path to universal health coverage in India: Overcoming the challenges of stewardship and governance. PLoS Med 2019;16:e1002759.

18. Chikkamath V, Nagappa AN. Pradhan Mantari Jan Aushadi Kendrademonetarization of medicine prices in India. J Gen Pract 2016;4:1-5.

19. Undergraduate Curriculum-Volume 1 by Medical Council of India. Available from: https://www.nmc.org.in/wp-content/uploads/2020/01/ UG-curriculum-Vol-I.pdf. [Last assessed on 2021 Feb 13].

20. Roy V, Rana P. Prescribing generics: All in a name. Indian J Med Res 2018;147:442-4

21. Panayappan L, Jose JM, Joseph JG, Jayapal K, Saju S, Kumar KK. Prescription audit and prescribing indicators: A review. J Bio Innov 2017;6:542-7. 